\title{
Prevalence of and associated factors with Trichomoniasis among women from quilombo communities in Brazil
}

\author{
DIAS JA*; MIRANDA AE; CRUZ LS; LUCIANO TV; D'SANTANA LP; MUSSO C; SANTOS MC \\ Federal University of Espirito Santo.
}

*E-mail: dias.saude@gmail.com

Background: The trichomoniasis is a nonviral sexually transmitted infection and it is associated with adverse reproductive health outcomes and risk of other STI.

Methods: A total of 289 Afro-descendants women, residents in quilombos (semi- isolated communities of descendants of African slaves in Brazil) were included in the study from March 2016 until April 2017. They answered an interview including demographics, behavior and sexual questions. During gynecologic examination were collected cervical cells for cytology and for testing Trichomonas vaginalis using a polymerase chain reaction (Quiagen ${ }^{\circledR}$ ). Chi square test was used to compare categories data and logistic multivariate analysis were used to assess associated factors of trichomoniasis.

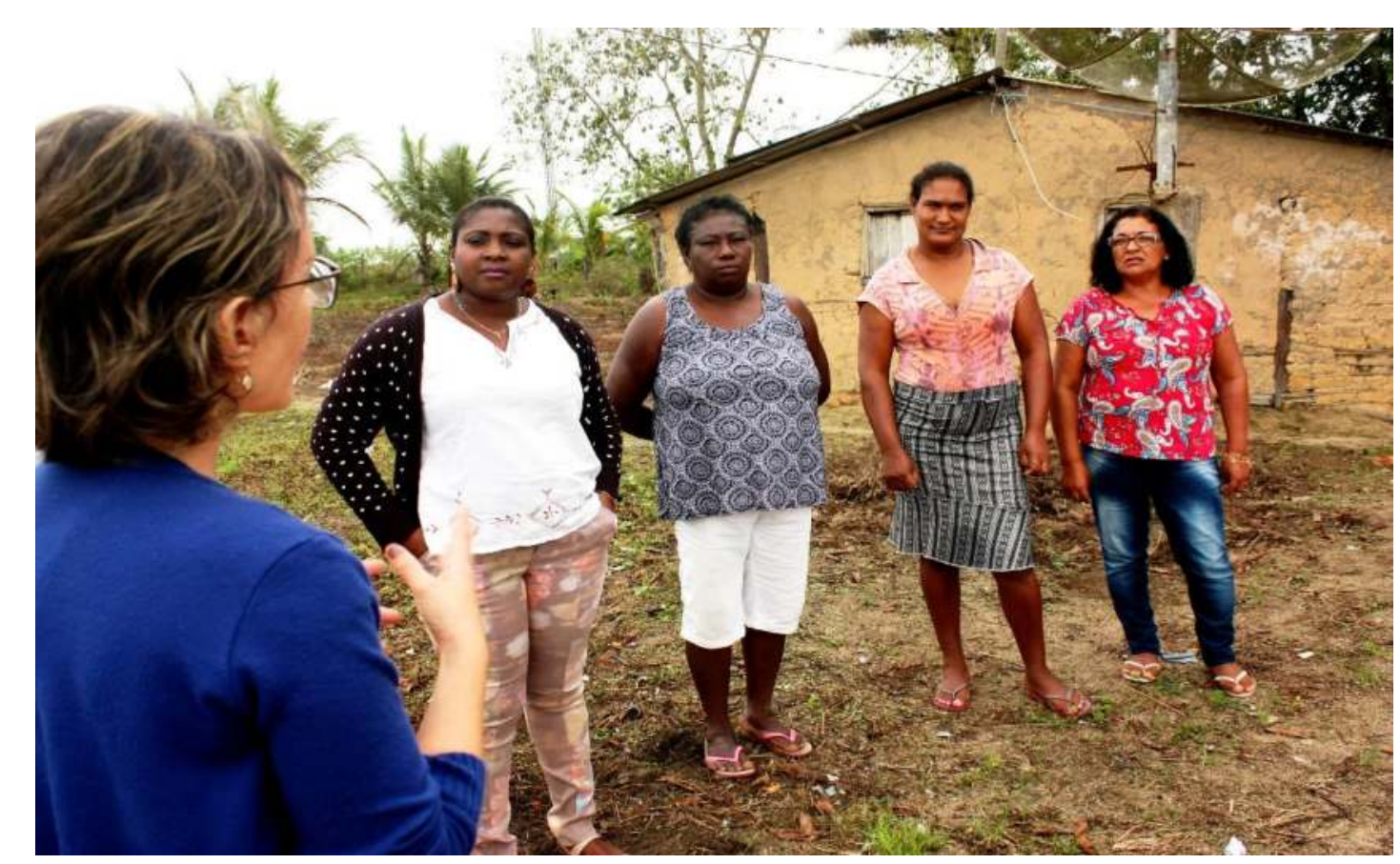

Quilombo comunity in Conceição da Barra - State of Espírito Santo - Brazil; 2017
Results: Data showed 4.5\% (Cl95\%:2.5- 7.6) of trichomoniasis among women. The average age were 41 years old (SD 14), 201 (70\%) had from 0 to 8 years of education; 183 (63\%) lived more than $25 \mathrm{Km}$ away from urban area of the city.

A total of $218(76 \%)$ reported not drinking alcohol, and 277 (97\%) did not used illicit drugs; 169 (60\%) reported the first sexual intercourse at $>=15$ years old. Regarding their partners, the age at first intercourse was younger than 20 years old in 120 (42\%) cases, 128 (54\%) reported having 2-5 male partners during life time. A total of $218(77 \%)$ did not use condom and $217(76 \%)$ denied having anal sex.

The analysis identified difference statistically significant among: condom use $(p<0,015)$, first sexual intercourse at $>=15$ years old $(p<0,020)$, alcohol $(p<0,001)$, and anal sex $(p<0,045)$. Alcohol abuse was the only factor associated with trichomoniasis in the final logistic model $(p<0.004$; OR:6.71;CI95\%:1.85-23.80).

Conclusions: The alcohol abuse can be responsible for unprotected sex and may contribute to trichomoniasis and other STI in the quilombo communities. These women have less access to education and are socially vulnerable and prevention strategies should be focuses on them.

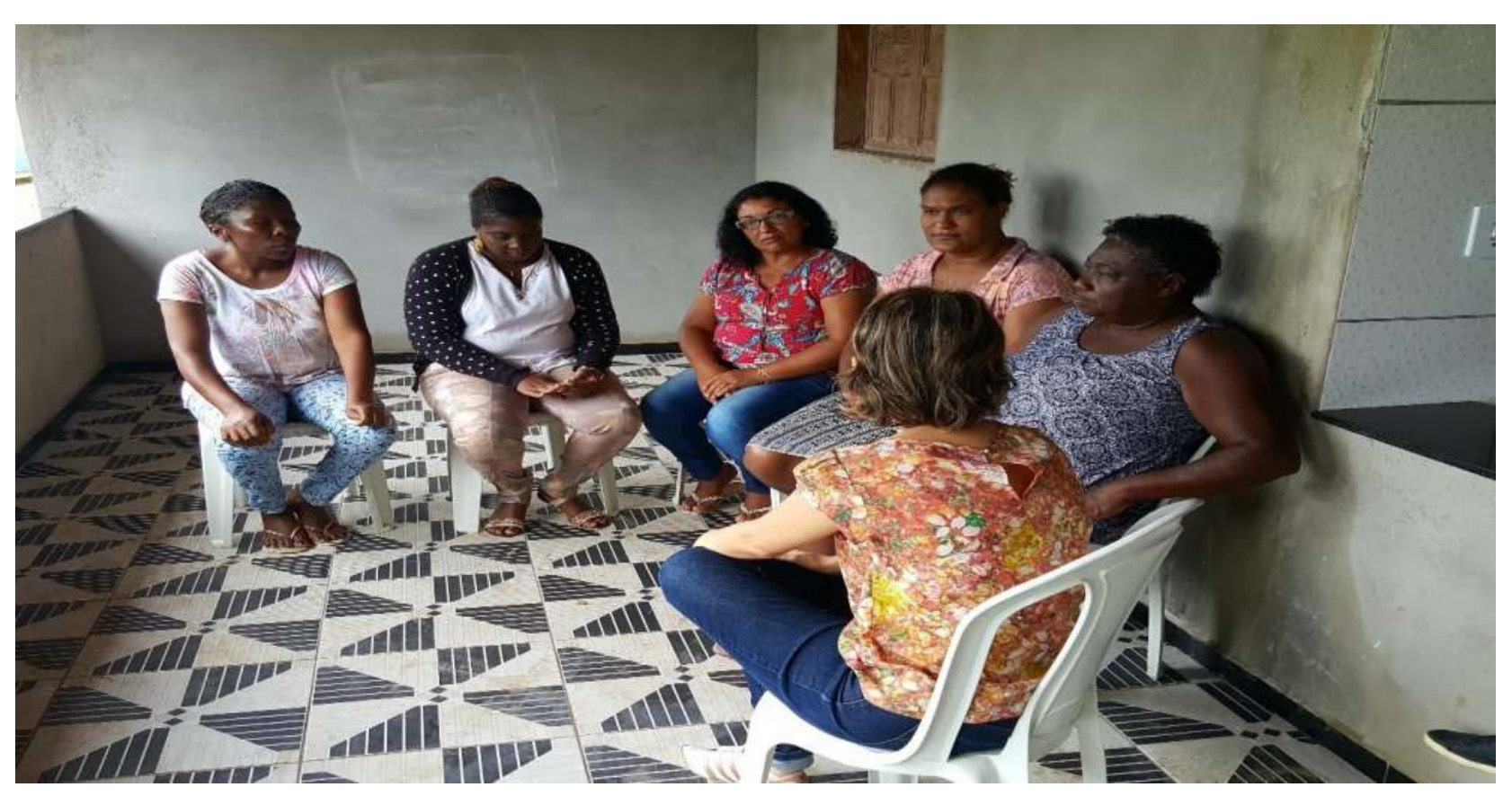

